Received Date : 19-Nov-2015

Revised Date : 19-Mar-2016

Accepted Date : 14-May-2016

Article type : Original Article

\title{
INTIMATE PARTNER VIOLENCE AND PREGNANCY INTENTIONS: A QUALITATIVE STUDY
}

Submission to Journal of Clinical Nursing: Original research article.

Title: Intimate Partner Violence and Pregnancy Intentions: A Qualitative Study.

Dr Kathleen Baird ${ }^{\mathrm{a}} \mathrm{RM}$ PhD (Corresponding Author)

Director of Midwifery and Nursing Education, Women's \& Newborn \& Children's Services/SaPS/Gold Coast University Hospital

$\mathrm{Ph}:+61733821198$ । M: 0424395885

Email: k.baird@griffith.edu.au

Professor Debra Creedy ${ }^{\mathrm{a}} \mathrm{RN}$ PhD

Professor of Perinatal Mental Health

Email: d.creedy@griffith.edu.au

Dr Theresa Mitchell

Associate Professor of Nursing (Patient Experience)

Email: t.mitchell@worc.ac.uk

${ }^{a}$ School of Nursing and Midwifery / Menzies Health Institute Queensland/ Griffith University

University Drive, Meadowbrook, Queensland, Australia, 4131

${ }^{\mathrm{b}}$ Institute of Health \& Society, University of Worcester, Worcester, England.

Funding Sources: Nil

This article has been accepted for publication and undergone full scientific peer review but has not been through the copyediting, typesetting, pagination and proofreading process which may lead to differences between this version and the Version of Record. Please cite this article as an 'Accepted Article', doi: 10.1111/jocn.13378

This article is protected by copyright. All rights reserved. 


\section{ABSTRACT}

\section{Aim and Objective}

In this qualitative study we explored women's pregnancy intentions and experiences of intimate partner violence before, during and after pregnancy.

\section{Background}

Unintended pregnancies in the context of intimate partner violence can have serious health, social and economic consequences for women and their children.

\section{Design}

Feminist and phenomenological philosophies underpinned the study to gain a richer understanding of women's experiences.

\section{Methods}

Eleven women who had been pregnant in the previous two years were recruited from community-based women's refuges in one region of the United Kingdom. Of the eleven women, eight had unplanned pregnancies, two reported being coerced into early motherhood, and only one woman had purposively planned her pregnancy. Multiple in-depth interviews focused on participants' accounts of living with intimate partner violence. Experiential data analysis was used to identify, analyse and highlight themes.

\section{Results}

Three major themes were identified: men's control of contraception, partner's indiscriminate response to the pregnancy, and women's mixed feelings about the pregnancy. Participants reported limited influence over their sexual relationship and 
birth control. Feelings of vulnerability about themselves and fear for their unborn babies' safety were intensified by their partners' continued violence during pregnancy.

\section{Conclusion}

Women experiencing intimate partner violence were more likely to have an unintended pregnancy. This could be attributed to male dominance and fear, which impacts on a woman's ability to manage her birth control options. The women's initial excitement about their pregnancy diminished in the face of uncertainty and ongoing violence within their relationship.

\section{Relevance to clinical practice}

Women experiencing violence lack choice in relation to birth control options leading to unintended pregnancies. Interpreting the findings from the victim-perpetrator interactive spin theory of intimate partner violence provides a possible framework for midwives and nurses to better understand and respond to women's experiences of violence during pregnancy.

\section{KEYWORDS}

Intimate partner violence, feminism, phenomenology, midwifery 


\section{INTRODUCTION}

Violence against women is a major public health issue and according to the World Health Organization [WHO] (2010) contributes to poor health of women. Intimate partner violence (IPV) includes many forms of physical, psychological and sexual violence, and a range of behaviours that may be used in isolation or in combination to control women (United Kingdom [UK] Department of Health, 2010). Experiencing violence at any time in a woman's life can result in harmful health problems, but violence during pregnancy is of special concern as the violence poses a threat to not only the woman but her fetus as well (Harne \& Radford 2008, Pallitto et al. 2005).

Worldwide, the prevalence of IPV during pregnancy varies. The exact incidence of IPV during pregnancy is difficult to estimate as many women are reluctant to disclose their experiences. Across developed countries, the prevalence of IPV during pregnancy has been estimated to be between $0.9 \%$ and $20.1 \%$ (Pallitto et al. 2013; Taillieu \& Brownridge 2010). In a study of IPV victimization in low and middle income settings across ten countries, García-Moreno and colleagues (2005) found that between thirteen $\%$ to sixty-one $\%$ of women interviewed reported physical IPV at some time in their life.

Women who are physically or sexually abused by their male partners report higher rates of reproductive health concerns. They are 16 times more likely to have a lowbirth-weight baby, more than twice as likely to have an abortion, almost twice as likely to experience postnatal depression, and in some countries, 1.5 times more likely to acquire HIV, compared to women who have not experienced IPV (WHO 2012). IPV at the time of conception and during pregnancy can be multi-faceted and have serious adverse health, emotional, social and economic implications for the 
woman and her family. However, the precise relationship between pregnancy intentions and IPV remains unclear.

\section{Background}

Pregnancy can trigger IPV or exacerbate ongoing violence (Pallitto et al. 2013). In a cross sectional survey with females aged between $16-29$ years attending family planning clinics in Northern California, Millar et al. (2010) found that over half the women $(53.4 \%)$ had experienced physical or sexual violence from an intimate partner. These abused pregnant women experienced an average of one injury per month. They also established that one in five women (19.1\%) reported pregnancy coercion, with contraception sabotage (which refers to covert attempts to prevent a woman from taking contraception) occurring for one in seven (15.0\%) women. Furthermore, more than two in five $(40.9 \%)$ women experienced at least one unintended pregnancy.

There is increasing evidence that violence against women is associated with an unplanned pregnancy (Bacchus et al. 2006, Charles \& Perreira 2007, Millar et al. 2010, Pallitto et al. 2005, Perales et al. 2009). Unintended pregnancies encompass two categories of pregnancy intentions: mistimed pregnancies that would be planned and wanted at a later date and unwanted pregnancies that are not wanted then or at a later date (Goodwin et al. 2000, Pallitto et al. 2005). The negative impact of unintended pregnancy is greater for unwanted pregnancy than a mistimed pregnancy (Mohllajee et al. 2007). However, a pregnancy that is both unplanned and unwanted by the male partner may trigger or escalate abuse (Bacchus et al. 2006). 
Women who experience sexual abuse and are coerced into sexual intercourse are less likely to have access to contraception, and more likely to have an unplanned pregnancy (Cripe et al. 2008). Indeed, it is estimated that up to $40 \%$ of women seeking a termination of pregnancy experienced sexual and physical violence (Utman et al. 2014). In a study of 2176 women in Peru, Cripe et al. (2008) found those who experienced physical and sexual violence in their lifetime had 1.63-fold increased risk of an unintended pregnancy after adjusting for maternal age and parity. Women with unwanted or mistimed pregnancies reported higher rates of physical violence during pregnancy than during the year before conception (Pallitto et al. 2005). Similarly, Díaz-Olavarrieta et al. (2007) reported that $71 \%$ of women abused women reported an increase in the severity of violence since becoming pregnant. Some authors suggest that IPV during pregnancy is a continuation of ongoing violence rather than related with pregnancy per se (Taillieu \& Brownridge 2010). However, very few researchers have explicitly explored women's accounts of their pregnancy intentions and experiences of IPV before, during and after pregnancy.

Exploring IPV and pregnancy intentions from a theoretical perspective may also provide useful insights for midwives and nurses caring for women experiencing violence. There are numerous theories of IPV but most tend to focus on causality and aetiology (Taillieu \& Brownridge 2010). Other theories focus on psychopathology of the perpetrator, or sociological forces related to power, poverty, poor conflict management, and the intergenerational transmission of violent behaviour (DeKeseredy, 2011). Furthermore, some proposed models focus on relationship interactions such as Walker's (1984) three stage cycle of violence (tension building, violence, and honeymoon) and Winstok's (2007) broader 4-level model (behaviour, 
situation, relationship, and socio-cultural context). However, these models do not consider the personal narrative whereby the psychological dynamic of each individual influences their violent interactions (Bensimon \& Ronel 2012). The victimperpetrator interactive spin (VPIS) theory of IPV is phenomenological in its orientation and attempts to represent the perspective of those involved "from within" the violent relationship (Bensimon \& Ronel 2012). VPIS focuses on possible meanings of the violence for each person as well as a mutual, interactive spin as a couple. For male perpetrators, violence could be used to assert power and control when they feel threatened. For the woman, violence may be driven by a strong need to be in a relationship while ignoring negative aspects of her partner's behaviour. The interactive spin derives from feelings of threat and helplessness shared by both (Bensimon \& Ronel 2012). Understanding violence from this theoretical perspective may be useful for midwives, nurses and other health professionals providing maternity care or supporting women experiencing IPV during pregnancy as well as their partners.

The purpose of the current study is to explore women's pregnancy intentions and their experiences of IPV across the perinatal period which has been neglected in previous research. Given that women experiencing violence do not freely disclose, and violence may commence or escalate at any time before, during and after pregnancy, a qualitative approach where participants can develop a trusting relationship with the researcher over time is warranted. Furthermore, findings will be considered through application of the victim-perpetrator interactive spin of IPV to provide a potentially useful framework for clinicians and better inform the support and interventions offered to pregnant women experiencing violence. 


\section{METHODS}

\section{Study design}

The researchers used a feminist phenomenology design to guide the study. A feminist, phenomenological paradigm was adopted as it is naturalistic, with an ontological principle that maintains that the world is not objective and discovered but socially constructed (Denzin \& Lincoln 2008). As an approach, phenomenology seeks to reveal how human awareness is implicated in the production of social action, social situations and social worlds (Denzin \& Lincoln 2008). The intention of combining the philosophies of feminism and phenomenology was to gain a deeper understanding of the phenomena of women's lived experiences of intimate partner violence. The concept of the 'lived body' clearly has resonance in the sphere of women's gender studies and for exploring the lives of those who have been marginalised or excluded.

Adhering to feminist principles, the women were considered 'expert' in relation to their experience of violence and abuse (Kelly et al. 1995). In accordance with the philosophies of feminist research, the principal investigator was a woman; the purpose of the work was to explore women's experiences; and to use the research findings to help women by informing the practice of midwives, nurses and other health professionals supporting women in clinical and community settings (Ribbens \& Edwards 1998). 


\section{Sample and setting}

Eligible participants were women, 18 years and older, currently pregnant or had been pregnant within the last two years, were separated from their partner at the time of the interviews, and accessing support services. Due to the sensitivity of the topic, consideration was given to the safety and appropriateness of the venue. All interviews were conducted in the safety of the women's refuge or a community-based children's centre.

\section{Procedure}

Participants were recruited through two women's support agencies in South West of England. All the staff working in the refuge were working directly with the women were briefed about the study. Recruitment was by posters placed in the women's refuge. Interested women met with the researcher at the refuge, received information about the study, had any questions answered, and gave informed consent. Following consent, multiple in-depth interviews were conducted with the women. The first interview was conducted seven days following recruitment, thereby allowing time for each woman to consider her involvement. Participants were aware they could withdraw from the study at any time and have a support worker present during the interviews if they wished. None of the women elected to do so. All the women who participated in the interviews received a $£ 10.00$ shopping voucher. The voucher was not seen as an incentive to take part; but a small token of thanks for their time and willingness to participate in the study.

In accordance with feminist principles, the interview aimed to be free flowing, iterative and conversational in nature. The initial questions were always a pre-amble such as 'Tell me a little bit about you'. It was important to avoid what is referred to as 
a 'smash and grab' interview, meaning getting in, doing the interview, and getting out without any real interest in participants of the study (Liamputtong, 2007).

The majority of women talked openly and freely about their experiences. Only two participants were slightly tentative at the beginning of their interview. On both occasions, using opening questions such as 'tell me a little bit about your family' and 'how did you meet your partner' were used with good effect to relax both participants. The interviews focused on participants' unique accounts, appreciating their different experiences and interpretations of becoming pregnant and living with IPV. During their interviews the women communicated the need to talk about their life and relationship prior to the violence and abuse. In hindsight, such disclosures were extremely helpful, as these facilitated a fuller understanding of the context of their lives. It seemed important for all the women to be known as individuals who went beyond being caught in the cycle of an abusive relationship.

The first author conducted all the interviews, which were digitally recorded. The number of interviews with each woman varied according to availability, well-being, carer commitments, and desire to participate in more than one interview to talk about her experiences. A total of 18 interviews were conducted with 11 women. Each interview lasted on average of one hour. The principle of on-going negotiation was always respected prior to commencing an interview. Data were collected over a period of 12 months. 


\section{Ethical considerations}

Ethical approval was obtained through the South West of England NHS Local Human Research Ethics Committee (08/H0102/70). Pseudonyms were used throughout all stages of the study. Participation in the research was voluntary. Informed consent was obtained prior to starting the interviews.

\section{Data Analysis}

Experiential data analysis was used to identify, analyse and highlight themes within data (Braun \& Clarke 2006). By utilising experiential analysis, the individual meaning of women's experiences were acknowledged, whilst also considering how the broader social context impinged on such meanings (Braun \& Clarke 2006). The analysis did not focus exclusively on individual philosophy but also considered the constructive contexts that enabled participants' accounts to be understood. Using indepth interviewing allowed for a deeper exploration of participants' experiences.

Experiential data analysis is reflective; in which recorded experiences are compiled, reduced, and examined for their interactions and basic themes. The more significant experiences are then extracted from the less significant within a system of meaning (Reinharz, 1992). Parts are then brought together to make new wholes while ensuring the analysis stayed true to the women's spoken words. Experiential analysis allowed for the individual meaning of women's experiences to be visible, whilst considering how the broader social context impinged on such meanings (Braun and Clarke, 2006). There are five stages to Reinharz's experiential data analysis (1992). Stage one comprises of transcribing the interviews verbatim, with the researcher also including their own field notes and interpretations from the interviews. Stage two includes repeated reading of the interview transcripts, along 
with careful listening of the women's experiences. The researcher recreates her conversations with the women noting the women's emotional state, allowing for the interpretations to become more personal. During stage three this deeper understanding is then transformed into conceptual themes, capturing the essence of each woman's experience. The themes emerge from a dialectical process of moving between backgrounds of intersubjective or shared meaning. As the researcher's interpretations become clearer, similar themes may merge into larger essential themes. Stage four takes into account the essential themes, which are then transformed into a meaningful written document enabling new understandings to be publicly expressed. Stage five, comprises of the reader performing the process of understanding, where interpretations are created out of the experiences of the participants. The main themes are then further developed and reviewed, resulting in another set of themes being developed (Braun \& Clarke 2006). The principal researcher $(\mathrm{KB})$ conducted the interviews and performed the data analysis.

The main objective data analysis phase of the study was to be as faithful as possible to the women's stories. Lincoln and Guba (1985) suggest credibility within qualitative research can be achieved by accurately interpreting the participant's experience. All participants were offered the opportunity to review their interview transcripts, thereby offering participant validation. Confirmability of the findings were also substantiated by the other members of the research team (Bryman, 2008) who also had the opportunity to read all the interview transcripts. 


\section{Results}

All participating women were living apart from their partners, and had experienced IPV during their pregnancy in the previous two years. Ages of participants ranged from 20 to 38 years (see Table 1). Two participants were married and nine were in a de facto relationship. The ages of children ranged from eight weeks to thirteen years old and all accompanied their mother to the refuge. Experiences of abuse included sexual, emotional, extreme control, and physical abuse. In many cases several different types of violence were experienced simultaneously. The length of relationships with an abusive partner varied from 3 to 15 years. Two women had children from a previous relationship.

\section{Pregnancy intention}

Eight of the eleven women experienced an unintended pregnancy; two women reported being bullied by their partner until they agreed to a pregnancy, and one woman purposively planned her pregnancy with her partner. Three major themes were identified: men's control of contraception use, partners' indiscriminate responses to the pregnancy, and women's mixed feelings about the pregnancy.

\section{Men's control of contraception use}

Five women reported that their partners skilfully exercised birth control sabotage and overt pregnancy coercion, by placing undue pressure on them to commit to motherhood before they felt ready. This behaviour included active bullying tactics. All women reported violence before pregnancy and their partners did not alter their 
violent behaviour towards them during pregnancy. None of the women reported feeling cherished during their pregnancy.

Several women appeared to blame themselves for the pregnancy. Some participants openly acknowledged they did not take control of their own contraceptive use and attributed this to living a chaotic lifestyle. Some construed themselves as being weak for 'allowing' themselves to become pregnant, rather than recognising their resilience and strength of carrying their baby to term.

The women reported their partners often contested the use of contraception. For example, Nicola believed her controlling and violent partner bullied her into motherhood. Once pregnant, her partner used her pregnancy as another form of coercive control to persuade her to set up home with him. Nicola admits that her use of contraception was sporadic and indiscriminate, as her abusive and controlling partner would become enraged if he thought she was trying to avoid conception.

\begin{abstract}
Well he forced me to get pregnant because he wanted loads of children. He knew once I was pregnant, he could convince me to move out of my family home and move in with his family. I tried to use contraception but it was very haphazard, as it always resulted in a big fight with him losing his temper and me suffering the consequences. I was only 18 and did not really want a baby, although when I was pregnant, it was OK, I just dealt with it (Nicola).
\end{abstract}

For many women, stressful life events contributed to the pregnancy. Kirsty suffered acute anxiety, and required hospitalisation. Following her discharge from hospital her partner took control of all her medications including the contraception pill telling her she was incapable of remembering to take her medication.

There were some days when I thought to myself I don't remember taking the pill and I said to him oh did I take the pill

This article is protected by copyright. All rights reserved. 
today? Yeah, you took it, I gave it to you. Yet all the time he knew I hadn't taken it. This manipulation went on for a couple of weeks and that's basically how I ended up pregnant (Kirsty).

Partners' indiscriminate responses to the pregnancy

There were various responses from male partners when the women revealed they were pregnant. Some male partners were initially pleased with the news of an impending pregnancy. However in the main, pregnancy seemed to be the channel, which allowed the men to increase their control. For Kirsty (described above), even though her partner planned the withholding of contraception, he refused to acknowledge the pregnancy once it was confirmed. Another woman reflected on her partner's enthusiasm to start a family,

I can remember he seemed obsessed with having a family ... he couldn't wait to be a dad; that was all he talked about. He was really pushy about it. He just kept on and on, talking about it all the time, he kept saying, oh we can have a baby it will be great (Tracey).

Regardless of the male partners' initial enthusiasm about the pregnancy, many men showed no paternal interest or involvement as the pregnancy progressed.

You know for someone who had gone on about wanting to be a dad, once I was pregnant, he wasn't very nice. He was not interested in antenatal appointments, he didn't want to read any books, he didn't want to go baby shopping, he just had no interest in the pregnancy; the only thing he seem concerned about was my weight gain (Julia).

Tracey was surprised by her partner's positive reaction and obvious delight to the news of the unplanned pregnancy. Looking back she now realised that he shrewdly used the news of her pregnancy as another means to control her decision-making. 
Tracey was unsure whether to continue with the unplanned pregnancy due to continuing violence; however, she felt compelled to continue with the pregnancy once her partner told family and friends about the pregnancy without consulting her.

He could not wait to tell everyone about it, he rushed to tell my parents. Even if I wanted to have an abortion I could not, not when he had told everyone. Although, to be honest, I probably would never have had an abortion as I really wanted to be a mum (Tracey).

Other women reported similar behaviours. In some cases women reported that their male partners were unpredictable in their feelings towards the pregnancy. Some partners frequently changed their mind about whether they wanted the woman to continue with her pregnancy.

No, the pregnancy was not planned, but when I told him about being pregnant his first reaction, was great, and I had hoped he would change the way he treated me. However, about 2 days later he started telling me he wished I would miscarry or that I should go and have an abortion - I was so confused (Sarah).

Yeah he was happy at first, but then sometimes he wasn't, he told me to get an abortion, so I did not know where I stood (Lisa).

Other women reported overt violence in response to news about the pregnancy. For example, Kirsty's partner responded to the news of her pregnancy with anger and violence.

He actually accused me of sleeping with other people, kept telling me to get rid of it... he was so cold towards me, yeah, told me to get rid of the baby. Um He actually beat me when I told him about the pregnancy (Kirsty).

Several women believed their partners' behaviours were not motivated by their desire to have children; rather, their behaviours were associated with increased 
domination and control. They used the pregnancy to bind the women deeper to the abusive and violent relationship. This may suggest the men perceived pregnancy as a means of increasing the women's vulnerability and reliance on them.

\section{Women's mixed feelings about their pregnancy}

Participating women spoke about the mixed emotions they experienced during their pregnancy. Many attributed these feelings to living in a violent relationship. They desperately wanted to enjoy the prospect of motherhood but their violent living situation impacted upon their optimism for their impending birth.

When I was pregnant, it was hard to actually distinguish the feelings that I had, between the happiness of feeling those first movements to the fear and frustration of the situation I was in. But you know now I am out of that situation obviously I look back and say why did I stay but at the time when you are there in that situation it's hard to understand your feelings yourself (Louise).

Even when the pregnancy was planned the initial excitement the women felt appeared to diminish quickly, especially when their male partner showed no paternal interest or took no pleasure in the pregnancy. One participant had experienced psychological and emotional abuse from her partner since the early days of their marriage but there had never been any physical violence until she was five months pregnant.

Even though I was not quite ready, I thought if we had a baby that he would sort his life out. I had hoped and prayed that he would start to think about the way he behaved, that he would become more caring and considerate, if I was pregnant, that would make a man of him, and how naïve was I? (Susan). 


\section{DISCUSSION}

This study reported on the retrospective perspectives of women becoming pregnant in a violent relationship. Few studies have reported on women's reflections on their pregnancy intentions and experiences of violence during pregnancy. The findings revealed the complexity of emotions experienced by women in response to unpredictable behaviours of their partners and the danger they faced with increasing violence.

In this study, 8 of the 11 women did not plan their pregnancies and two agreed to become pregnant only after relentless pressure and bullying from their partner. In line with previous research, the current findings revealed a perceived relationship between partner violence and unintended pregnancy. Previous quantitative research identified that women were more likely to have an unintended pregnancy if they had been physically or sexually abused by an intimate partner (Gazmararian et al. 1995; Goodwin et al. 2000; Pallitto et al. 2005; Saltzman et al. 2003). In a large US-based study of nearly 40,000 women Goodwin et al. (2000) revealed that only a third of women who reported abuse in the previous year, at the time of conception, or during their pregnancy, had planned the pregnancy.

Consideration of the findings through application of the victim-perpetrator interactive spin (VPIS) of IPV (Bensimon \& Ronel 2012) reveals several insights for practice. IPV predominantly refers to male violence towards women and this was certainly evident in the current study. While the VPIS acknowledges that both partners are involved in the dynamic of violence, this perspective does not blame the victim or absolve the perpetrator from their actions (Bensimon \& Ronel 2012). Not blaming the 
victim is of particular importance for clinicians who need to remain supportive and sensitive to the needs of pregnant women in their care.

Of interest to the current study are the four motives which underpin the VPIS of: extreme self-centredness; narrowed perceptions and feelings; inability to empathise with others; and a preoccupation with "I can" and "I must" drives for action (Bensimon \& Ronel 2012). This deviant mindset allows the man to break the norms usually expected in intimate relationships and be demanding, threatening and violent (Ronel 2011).

According to Bensimon and Ronel (2012) the pregnant woman and her violent partner experience a personal and mutual spin. Both share feelings of threat and helplessness. IPV is underpinned by extreme self-centredness. The man sees only his own needs and is jealous and possessive of his partner who he sees as an object. When the perpetrator feels a loss of control and powerlessness, he is motivated to regain control ("I must”). Participants in the current study made numerous references to their partners' increasing need for control and attention, and disregard for the growing fetus. Participating women reported increasing levels of controlling behaviour by their male partner, which could be interpreted as a possible attempt to address his own feelings of insecurity.

According to the VPIS theory, self-centredness by the woman may sometimes be expressed as an urgent need for physical contact and warmth that can only be fulfilled by her partner. Participants in the current study expressed hopes that their love and the pregnancy would change their relationship for the better, even though 
this did not happen in reality. We found that even in the one case where the pregnancy was planned, violence was still evident. Pallitto et al. (2005) also found that even when a pregnancy was planned, it may be perceived as threatening to a partner, leading to jealously toward the unborn fetus, and increased violence. Some participants in the present study held hopes for a protective nurturing response by male partners but instead experienced inconsistent and unpredictable behaviour that reflected anger, neglect, and blame that was highly stressful for the women.

Our findings align with the VPIS interpretation, which suggests that social factors such as maternal age and education are not protective against violence. In the current study, 2 of the 11 women were educated to degree level and were over thirty years of age at the time of their first pregnancy. This finding differs from other reports that socially disadvantaged women often experience higher rates of physical violence (Gamararian et al. 1995, Goodwin et al.. 2000, Saltzman 2003). Goodwin et al. (2000) found a link between abuse and maternal characteristics, with levels of abuse significantly more prevalent among younger women who were unmarried and had less educational attainment. These contrasting findings call into question the reliance on assessing socio-demographic risk factors for IPV in clinical practice. Understanding IPV from a theoretical perspective highlights the importance of understanding a woman's psychological commitment to the relationship as part of the midwifery and nursing assessment process and approaches to care.

For the majority of women, their pregnancy was unplanned, and yet they all made the decision to continue with the pregnancy. According to the VPIS theory, their behaviour may be related to their sense of powerlessness, narrowed perceptions of alternative choices, and self-centred desire for love. The current study established 
that women living in a violent relationship had limited influence over their sexual relationship or birth control options. These circumstances potentially increased their risk of becoming pregnant unintentionally compared to women living in non-violent relationships (Goodwin et al. 2000). However, it should be noted that even though many women in this study had an unplanned pregnancy, this did not equate to the pregnancy being unwanted by them. Nevertheless, their decision to continue with an unplanned pregnancy could be attributed to compromised decision making and fear

of reprisals from their male partner. Many of the women believed (and hoped) that impending fatherhood would change the violent behaviour of their male partners; however, this did not happen. During pregnancy, male partners continued to be physically and emotionally violent, with the violence increasing in the postnatal period for the majority of women.

\section{Relevance to clinical practice}

The VPIS approach may enable midwives, nurses and other health professionals to reframe the violence from the perspective of "within" the couple relationship. A deep sense of powerlessness and loss of control underpins the male partner's need to dominate. Both the man and woman act in different self-centred ways with narrowed perceptions of alternative actions and responses. Understanding this perspective may enable midwives and nurses to empathise with women in their care, provide insights, and assist women to see alternatives to their current circumstances.

Given the large number of women who seek antenatal care each year, it is important that midwives and nurses, as well as other relevant health care professionals such as general practitioners, and staff working in accident and emergency departments 
to recognise and acknowledge the key role they can play in acknowledging the violence, and providing help and support to women experiencing IPV. There is no doubt that IPV is challenging and complex however, given the link between IPV and pregnancy, health, community and justice services must continue to provide an effective and coordinated response to the identification and management of IPV and support of women and their children. It is important that midwives recognise that not every pregnancy is planned or conceived out of love, for many of the women in this study, their pregnancy was unintentional or they were bullied into motherhood by domineering partners before they felt ready. These women did not experience the feelings of happiness and hope that many women do when a pregnancy is planned and wanted, instead they experienced feelings of entrapment and fear.

Women with an unplanned pregnancy are more likely to delay or minimise access to appropriate antenatal care (Pallitto et al. 2005). When women do seek care, it is essential for midwives and nurses to offer support and informed understanding. Recognising the need for a better response to IPV by health care staff has led to regulatory bodies of many countries such as the UK and Australia to introduce awareness-raising campaigns, and develop policy guidelines for routine antenatal and postnatal enquiry for IPV (Australian Health Ministers' Advisory Council 2012, National Institute Clinical Excellence, 2014). However, it is vital that such policies are supported with continued education for midwives and nurses, multi-agency training, and robust referral pathways following disclosure of women about their experiences of IPV.

Midwives and nurses should be skilled in their communication and responses so that women do not experience routine enquiry about violence as merely a tick box exercise. A theoretical perspective enables a richer, more purposeful response and 
may provide new insights for midwives and nurses supporting women experiencing violence. For example, staff could help women to achieve a broader understanding of their situation, an appreciation that a range of choices are available to them, and foster social support. Midwives and nurses could work with women to help them reframe their situation and diminish their emotional reliance on their violent partner. Accessing childbearing women who are experiencing IPV can be challenging for midwives, nurses, and other health professionals, nevertheless, every effort needs to be made to enable women to feel safe and supported in sharing their stories so a detailed understanding can be obtained and targeted support offered.

There are some limitations of the study that should be acknowledged. Although women of different ages, parity and ethnic backgrounds volunteered to participate, it is important to acknowledge that their views may differ from those women who remain in violent relationships. The study was also retrospective and relied on women's recollection of events.

\section{CONCLUSION}

The findings of this study provide insight into women's pregnancy intentions and experiences of abuse before, during, and after pregnancy within the context of a violent relationship. IPV and unintended pregnancy could be attributed to male dominance and fear, which impact on a woman's ability to manage her birth control choices. A planned pregnancy was not protective against further violence. Male partners reportedly demonstrated coercive and controlling behaviours, and were inconsistent in their attitudes towards the pregnancy, placing the women at 
continued risk for violence. The women's initial excitement about the pregnancy diminished in the face of uncertainty and ongoing violence within the relationship.

Theoretical perspectives such as VPIS can inform practice as well as future quantitative and qualitative research to better understand psychological processes that contribute to women remaining in violent relationships minimise the number of unintended pregnancies; and enable midwives and nurses to better support women in a violent relationship.

SUMMARY BOX: What does this paper contribute to the wider global clinical community?

- Women in a violent relationship have limited control over their sexual relationship and/or birth control options

- Living with intimate partner violence increases the risk of unintended pregnancy

- A planned pregnancy is not protective against further violence.

- Application of the victim-perpetrator interactive spin theory of IPV enables clinicians to reframe the violence from the perspective of "within" the couple relationship.

\section{REFERENCES}

Australian Health Ministers' Advisory Council (2012) Clinical Practice Guidelines: Antenatal Care - Module 1. Australian Government, Department of Health and Ageing. Retrieved from http://www.health.gov.au/antenatal

Bacchus L, Mezey G \& Bewley S (2006) A qualitative exploration of the nature of domestic violence in pregnancy. Violence Against Women 12, 588-604. 
Bensimon M \& Ronel N (2012) The flywheel effect of intimate partner violence: A victim-perpetrator interactive spin. Aggression \& Violent Behavior 17, 423-429.

Braun V \& Clarke V (2006) Using thematic analysis in psychology. Qualitative Research in Psychology 3, 77-101.

Bryman A (2008) Social research methods $3^{\text {rd }}$ Edition. Oxford University Press. Oxford.

Charles P \& Perreira, KM (2007) Intimate partner violence during pregnancy and 1 year postpartum. Journal of Family Violence 22, 609-612.

Cripe SM, Sanchez SE, Perales MT, Lam N, Garcia P \& Williams MA (2007) Association of intimate partner physical and sexual violence with unintended pregnancy among pregnant women in Peru. Social Issues in Reproductive Health 100, 104-108.

Díaz-Olavarrieta C, Paz F, Abuabarak K, Martinez Ayala HB, Kolstad K \& Palermo T (2007) Abuse during pregnancy in Mexico City. International Journal of Obstetrics and Gynecology 97, 57-64.

Denzin NK \& Lincoln YS (2008) Strategies of Qualitative Inquiry, $3^{\text {rd }}$ Edition. Sage Publications, London.

DeKeresdy WS (2011) Violence against women: Myths, facts, controversies. University of Toronto Press, Higher Education Division. Retrieved from http://www.utppublishing.com/Violence-Against-Women-Myths-Facts-

Controversies.html

El Kady D, Gilbert WM, Xing G \& Smith LH (2005) Maternal and neonatal outcomes of assaults during pregnancy. Obstetrics \& Gynaecology, 105, 357- 63.

García-Moreno C, Henrica AFM, Ellsberg, JM, Heise L \& Watts C (2005). WHO multi-country study on women's health and domestic violence against women: initial results on prevalence, health outcomes and women's responses. World Health Organization, Geneva.

Gazmararian JA, Adams MM, Saltzman LE, Johnson CH, Bruce FC, Marks JS, Zahniser SC, \& PARMS Working Group (1995) The relationship between pregnancy 
intendedness and physical violence in mothers of newborns. Obstetrics and Gynecology 85, 1031-1038.

Goodwin MM, Gazmararian JA, Johnson CH, Gilbert BC \& Saltzman LE (2000) PRAMS working group pregnancy intendedness and physical abuse around the time of pregnancy: Findings from the pregnancy risk assessment monitoring system, 1996 - 1997, Maternal \& Child Health Journal 4, 85- 92.

Harne L \& Radford J (2008) Tackling domestic violence: Theories, policies and practice. Open University, Maidenhead.

Kelly L. Regan L \& Burton S (1995) Defending the indefensible? Quantitative methods and feminist research. In Debates and issues in feminist research and pedagogy (Holland J, Blair M \& Sheldon S eds.) Multilingual Matters Ltd, Clevedon, pp $235-248$.

Liamputtong P (2007) Researching the vulnerable. Sage Publications, London.

Lincoln YS \& Guba EG (1985) Naturalistic inquiry. Sage Publications, Beverly Hills.

Millar E, Decker MR, Mc Cauley HL, Tancredi DJ, Levenson R., Aldman J, Schoenwal P \& Silverman JG (2010) Pregnancy coercion, intimate partner violence, and unintended pregnancy. Contraception 81, 316 - 322.

Mohllajee AP. Curtis KM, Morrow B \& Marchbanks PA (2007) Pregnancy intention and its relationship to birth and maternal outcomes. Obsetetrics \& Gynecology 109, $678-86$.

National Institute for Health and Care Excellence (2014) Domestic violence and abuse: how health services, social care and the organizations they work with can respond effectively, NICE public health guidance 50. Available at: https://www.nice.org.uk/guidance/ph50 (accessed 10 July 2015).

Pallitto CC, Campbell JC \& O'Campo P (2005) Is intimate partner violence associated with unintended pregnancy? A review of the literature. Trauma, Violence \& Abuse 6, 217- 235 .

Pallitto CC, Garcia-Moreno C, Jansen H A, Heise L, Ellsberg M \& Watts C (2013) Intimate partner violence, abortion, and unintended pregnancy: Results from the 
WHO Multi-country Study on Women's Health and Domestic Violence. International Journal of Gynecology \& Obstetrics 120, 3-9.

Peralas, MT, Cripe SM, Lam N, Sanchez E \& Williams MA (2009) Prevalence, types, and pattern of intimate partner violence among pregnant women in Lima, Peru. Violence Against Women 15, 224 - 250.

Reinharz S (1992) Feminist methods in social research. Oxford University Press, Oxford.

Ribbins J \& Edwards R (1998) Feminist dilemmas in qualitative research, public knowledge and private lives. Sage Publications, London.

Ronel N (2011) Criminal behaviour, criminal mind: Being caught in a criminal spin. International Journal of Offender Therapy and Comparative Criminology 55, 12081233.

Saltzman LE, Johnson CH, Gilbert BC \& Goodwin MM (2003). Physical abuse around the time of pregnancy: An examination of prevalence and risk factors in 16 states. Maternal and Child Health Journal 7, 31 - 43.

Taillieu T \& Brownridge D (2010) Violence against pregnant women: Prevalence, patterns, risk factors, theories, and directions for future research. Aggression and Violent Behaviour 15, 14-35.

United Kingdom Department of Health (2010) Responding to violence against women and children -the role of the NHS. The Report of the Taskforce on the Health Aspect of Violence Against Women and Children. Department of Health. London.

Utman N, Yasmin S \& Raees, M. (2014) Prevalence of domestic violence among women seeking abortion. Journal of Postgraduate Medical Institute, 28, 74-78.

Walker LEA (1984) Battered woman syndrome, Springer New York.

Winstok Z (2007) Toward an interactional perspective on intimate partner violence. Aggression \& Violent Behaviour 12, 348-363.

World Health Organization/London School of Hygiene and Tropical Medicine (2010) Preventing intimate partner and sexual violence against women. Taking action and generating evidence. World Health Organization, Geneva. Available at: 
http://www.who.int/violence_injury_prevention/publications/violence/9789241564007 _eng.pdf (accessed August 3 2015)

World Health Organization, Department of Reproductive Health and Research, London School of Hygiene and Tropical Medicine, South African Medical Research Council (2012) Global and regional estimates of violence against women.

Prevalence and health effects of intimate partner violence and non-partner sexual violence. Geneva: World Health Organization. Available at:

http://apps.who.int/iris/bitstream/10665/85239/1/9789241564625_eng.pdf (accessed August 3 2015).

This article is protected by copyright. All rights reserved. 
Table 1: Biographical characteristics of participants

\begin{tabular}{|c|c|c|c|c|c|c|c|}
\hline $\begin{array}{l}\text { Name } \\
\text { (Pseudonym) }\end{array}$ & Age & Occupation & $\begin{array}{l}\text { Highest } \\
\text { education } \\
\text { level }\end{array}$ & Children & Ages of children & Ethnicity & $\begin{array}{l}\text { Types of violence experienced in } \\
\text { relationship }\end{array}$ \\
\hline Tracey & 23 & Full time mother & $\begin{array}{l}\text { Secondary } \\
\text { school }\end{array}$ & 2 & $\begin{array}{l}22 \text { months \& } 8 \\
\text { months }\end{array}$ & White British & $\begin{array}{l}\text { Physical, verbal, sexual, controlling, } \\
\text { emotional and financial }\end{array}$ \\
\hline Julia & 35 & Full time mother & $\begin{array}{l}\text { Secondary } \\
\text { school }\end{array}$ & 3 & $\begin{array}{l}13,11 \text { years \& } 19 \\
\text { months }\end{array}$ & White British & $\begin{array}{l}\text { Physical, verbal, controlling, } \\
\text { financial and isolation }\end{array}$ \\
\hline Sarah & 34 & Full time mother & $\begin{array}{l}\text { Secondary } \\
\text { School }\end{array}$ & 1 & 2 years & White British & $\begin{array}{l}\text { Physical, verbal, emotional and } \\
\text { financial }\end{array}$ \\
\hline Jane & 36 & $\begin{array}{l}\text { Health care } \\
\text { assistant and } \\
\text { student }\end{array}$ & Degree & 3 & $\begin{array}{l}10 \text { years \& twins } 13 \\
\text { months }\end{array}$ & Indonesian & $\begin{array}{l}\text { Physical, verbal, emotional, sexual, } \\
\text { controlling and financial }\end{array}$ \\
\hline Susan & 32 & Home Carer & $\begin{array}{l}\text { Secondary } \\
\text { school }\end{array}$ & 2 & $\begin{array}{l}\text { (13 years previous } \\
\text { relationship) \& } 8 \\
\text { weeks }\end{array}$ & White British & $\begin{array}{l}\text { Physical, verbal, emotional, } \\
\text { controlling and financial }\end{array}$ \\
\hline Nicola & 22 & $\begin{array}{l}\text { Full time } \\
\text { mother }\end{array}$ & College & 2 & 2 years \& 9 months & White British & $\begin{array}{l}\text { Physical, verbal, emotional, } \\
\text { controlling, sexual and financial }\end{array}$ \\
\hline Wendy & 38 & Office manager & Degree & 2 & $\begin{array}{l}5 \text { years \& } 20 \\
\text { months }\end{array}$ & Indonesian & Physical and verbal \\
\hline Kirsty & 24 & Full time mother & College & 1 & 2 years & White British & $\begin{array}{l}\text { Physical, verbal, emotional, } \\
\text { controlling, sexual and financial }\end{array}$ \\
\hline Louise & 25 & $\begin{array}{l}\text { Part-time } \\
\text { waitress }\end{array}$ & $\begin{array}{l}\text { Secondary } \\
\text { school }\end{array}$ & 1 & 22 months & Black British & Physical, verbal and emotional \\
\hline Tamara & 34 & Full time mother & $\begin{array}{l}\text { Secondary } \\
\text { school }\end{array}$ & 4 & $\begin{array}{l}(12,8,5 \text { years } \\
\text { previous } \\
\text { relationships) \& } 14 \\
\text { months }\end{array}$ & White British & $\begin{array}{l}\text { Physical, verbal, emotionally and } \\
\text { controlling }\end{array}$ \\
\hline Lisa & 20 & Full time mother & $\begin{array}{l}\text { Secondary } \\
\text { school }\end{array}$ & 1 & 13 months & White British & $\begin{array}{l}\text { Physical, verbal, emotional, } \\
\text { controlling and financial }\end{array}$ \\
\hline
\end{tabular}

This article is protected by copyright. All rights reserved. 